\title{
Optokinetic Deficits in Albino Ferrets (Mustela putorius furo): A Behavioral and Electrophysiological Study
}

\author{
Klaus-Peter Hoffmann, Nicolaos Garipis, and Claudia Distler \\ Allgemeine Zoologie und Neurobiologie, Ruhr-Universität Bochum, Postfach 102148, D-44780 Bochum, Germany
}

We compared the horizontal optokinetic reaction (OKR) and response properties of retinal slip neurons in the nucleus of the optic tract and dorsal terminal nucleus (NOT-DTN) of albino and wild-type ferrets (Mustela putorius furo). In contrast to pigmented ferrets, we were unable to observe OKR in albino ferrets during binocular and monocular viewing using random dot full field stimulation and electrooculography (EOG). Observations during early postnatal life indicate that regular OKR is present in pigmented pups $3 \mathrm{~d}$ after eye opening but is absent at any stage during development in albino ferrets. Unilateral muscimol injections to inactivate all neurons in the NOT-DTN containing $\mathrm{GABA}_{\mathrm{A}}$ and $\mathrm{GABA}_{\mathrm{C}}$ receptors caused spontaneous horizontal nystagmus with slow phases away from the injected hemisphere in albino as well as in pigmented animals. Retinal slip neurons in the NOT-DTN of albino ferrets identified by antidromic activation from the inferior olive and orthodromic activation from the optic chiasm were well responding to intermittent bright light stimuli, but many showed a profound reduction of responsiveness to moving stimuli. The movement-sensitive neurons exhibited no clear direction selectivity for ipsiversive stimulus movement, a characteristic property of these neurons in pigmented ferrets and other mammals. Thus, the defect rendering albino ferrets optokinetically nonresponsive is located in the visual pathway subserving the $0 \mathrm{KR}$, namely in or before the NOT-DTN, and not in oculomotor centers.

Key words: optokinetic reaction; retinal slip neurons; nucleus of the optic tract; dorsal terminal nucleus of the accessory optic system; muscimol inactivation; antidromic activation

\section{Introduction}

The optokinetic reaction (OKR), a reflex stabilizing the image of the visual world on the retina, suffers a functional deterioration in albinos (Collewijn et al., 1985). Normally, monocular OKR in frontal eyed mammals such as ferrets, cats, and especially primates is symmetric, i.e., both stimulus directions elicit equally strong reactions. However, in these species OKR symmetry depends on normal binocularity in visual cortex, and therefore is prone to be disturbed by abnormal visual development. Because of the reduction of uncrossed retinal projections and the reduction of cortical binocularity in albino ferrets (Morgan et al., 1987; Akerman et al., 2003), we should expect changes in the OKR similar to the consequences of strabismus, deprivation, or decortication in other mammals (Cynader and Harris, 1980; Sengpiel et al., 1990). Monocular OKR should become more asymmetrical.

The neuronal substrate subserving the optokinetic reaction is very similar in all mammals. Direction-selective retinal ganglion cells project to retinal slip neurons in the nucleus of the optic tract and dorsal terminal nucleus (NOT-DTN), which in turn project to the inferior olive (IO), the dorsolateral pontine nucleus, the

Received Aug. 30, 2003; accepted March 12, 2004.

This work was supported by Deutsche Forschungsgemeinschaft Grant Sonderforschungsbereich 509. We thank H. Korbmacher, G. Reuter, and M. Möllmann for expert technical assistance and W. Blaszczyk for help with the graphics. The ferret pups were tested by $D$. Hupfeld.

Correspondence should be addressed to Prof. K.-P. Hoffmann, AllgemeineZoologie und Neurobiologie, Ruhr-Universität Bochum, Postfach 102148, D-44780 Bochum, Germany. E-mail: kph@neurobiologie.ruhr-uni-bochum.de.

DOl:10.1523/JNEUROSC1.0903-04.2004

Copyright $\odot 2004$ Society for Neuroscience $\quad 0270-6474 / 04 / 244061-09 \$ 15.00 / 0$ nucleus reticularis tegmenti pontis, and the nucleus praepositus hypoglossi (Hoffmann and Stone, 1985; Magnin et al., 1989). From there, visual information reaches the cerebellum, deep cerebellar nuclei, and the vestibular nuclei. The latter project to the motor nuclei innervating the extraocular muscles (for review, see Simpson et al., 1988). In most mammals retinal slip neurons of the NOT-DTN receive an additional visual input via the visual cortex and are characterized by their strong preference for ipsiversive stimulus movement. Neurons in the left NOT-DTN prefer movement to the left, and vice versa. Electrical stimulation at recording sites of retinal slip neurons produces optokinetic nystagmus with the slow phases directed toward the stimulated side (Collewijn, 1975; Schiff et al., 1988; Taylor et al., 2000; Hoffmann and Fischer, 2001). Similarly, inactivation of the NOT-DTN causes an impairment of the slow phase of OKR toward the lesioned side and leads to spontaneous slow phases toward the intact side (Kato et al., 1988; Schiff et al., 1990; Ilg et al., 1993; Inoue et al., 2000; Hoffmann and Fischer, 2001).

To further characterize the effects of albinism on the visual system of ferrets, we measured OKR during full field stimulation and found that albino ferrets are unable to perform regular optokinetic nystagmus. Thus, we refer to these animals as "optokinetically deficient." By electrophysiological recordings in the NOT-DTN and muscimol injections into this nucleus we attempted to characterize the neuronal deficit.

\section{Materials and Methods}

Animals. Behavioral tests were performed in 12 pigmented and 33 albino ferrets of both sexes ranging in age between 3 and 16 months. In addition, 
behavioral observations were made in two pigmented and six albino pups from the day of eye opening until $28 \mathrm{~d}$ of age. Four adult animals were purchased from Marshall Farms (North Rose, NY). The remainder were bred and raised in the animal facility of the Department of General Zoology and Neurobiology, Ruhr-University Bochum. All animals were group-housed with access to an outdoor enclosure. Care was taken to provide nesting material and hiding places as boxes and dark tubes so that the animals could avoid exposure to light. The experiments were approved by the local ethics committee and were performed in accordance with the European Communities Council Directive of 24 November 1986 (S6 609 EEC) and National Institutes of Health guidelines for care and use of animals for experimental procedures.

Behavioral tests with electro-oculography and video monitoring. During the behavioral tests the animals sat comfortably in a snug plastic tube with the head fixed by an individually fitted harness. Eye movements were recorded with varnish-coated $\mathrm{Ag}-\mathrm{AgCl}$ electrodes (diameter, 100 $\mu \mathrm{m}$ ) inserted subcutaneously under local anesthesia at the temporal canthus of the eyes. These wire electrodes were removed at the end of the recording session without any irritation of the skin.

To measure the response to optokinetic stimuli, the animals were placed in a drum ( $90 \mathrm{~cm}$ in diameter) covered with random dot patterns (fine pattern: dot size $2.3^{\circ}$; coarse pattern: dot size $10.7^{\circ}$ ). Luminance of the bright dots was $30 \mathrm{~cd} / \mathrm{m}^{2}$, and that of the black dots was $2 \mathrm{~cd} / \mathrm{m}^{2}$, resulting in a luminance contrast of $87 \%$. In addition, some animals were tested with bright dots projected via a planetarium on the homogenous surface of the drum. The drum was rotated in clockwise and counterclockwise direction at various stimulus speeds $(5,10,20,50$, and $100 \%$ sec) (cf. Hein et al., 1990). Eye movements were recorded over 30 or 60 sec periods during binocular and monocular viewing. Control measurements were performed either in darkness or with the pattern stationary.

Electro-oculography (EOG) signals were recorded at $100 \mathrm{~Hz}$ resolution, amplified, and stored in a personal computer for off-line analysis of the slope of the slow phase of OKR. Because the EOG signal could not be calibrated, the median of the slopes occurring during the recording period was calculated (in millivolts per second) and taken as relative measure of eye velocity. Data were tested for statistical differences using the Wilcoxon signed rank test and the Mann-Whitney $U$ rank sum test.

For the video observations in the ferret pups, the animals were placed on a small table under a transparent cover in the center of the drum. Head and body movements were recorded with a camcorder (Sony, Tokyo, Japan; CCD-repetition time 928E) during binocular stimulation with the coarse pattern (dot size $6-14^{\circ}$ visual angle depending on the exact position of the animal on the table) at 10,20,50, and $100 \%$ sec in clockwise and counterclockwise direction. Stimulus-related whole-body continuous turning or following reactions [optomotor response (OMR)] as well as head nystagmus were analyzed off-line.

Surgery. Placement of cannulas for the inactivation experiments and the electrophysiological recordings were performed under deep anesthesia. The animals were treated with $0.025 \mathrm{mg}$ atropine sulfate (Braun) and initially anesthetized with $40 \mathrm{mg} / \mathrm{kg}$ ketamine and $0.06 \mathrm{mg}$ xylazine (Rompun). After additional local anesthesia the animals were placed in a stereotaxic frame. A tracheotomy was performed for electrophysiological recordings. The animals were paralyzed with alcuroniumchloride (Alloferin) and artificially ventilated with nitrous oxide:oxygen as 3:1 and $0.1-0.3 \%$ halothane as needed. Otherwise anesthesia was maintained by additional application of ketamine. The skin overlying the skull was cut, the temporalis muscle deflected, and craniotomies were performed allowing access to the optic chiasm, the superior colliculus, and the pretectum. During the entire procedure heart rate, endtidal $\mathrm{CO}_{2}$, and body temperature were monitored and maintained at physiological levels.

The NOT-DTN was localized according to its position just lateral and anterior to the representation of the ventral and central-ipsilateral visual field in the superior colliculus. For the inactivation experiments the NOT-DTN was localized electrophysiologically using tungsten-in-glass microelectrodes as for the recording experiments. Then the recording electrode was replaced by a stainless steel cannula ( 26 gauge $\times 1$ inch) that later served as guide tube for the injection cannula. The guide tube was lowered so that the tip was $\sim 1 \mathrm{~mm}$ above the surface of the pretectum to avoid damage to pretectal tissue, and fixed to the skull with dental acrylic. The lumen of the guide tube was blocked with a mandrin when not in use. Then the wound was closed in appropriate layers and covered with antibiotic ointment (Nebacetin). After the animals had fully recovered, they were returned to their home enclosure. As a precaution they were treated with a broadband antibiotic (enrofloxacin, Baytril) for 1 week after surgery.

Pretectal inactivation. The pretectum was inactivated with muscimol in three albino and one pigmented ferrets. Approximately $3 \mathrm{~d}$ after surgery a Hamilton microliter syringe was placed within the injection cannula and connected to a calibrated vinyl tube. A total of $1 \mu \mathrm{l}$ of $0.1 \%$ muscimol in $0.9 \%$ saline was injected over $\sim 2 \mathrm{~min}$. The first eye movement recordings began within $2-4 \mathrm{~min}$ after injection.

After the last muscimol injection $0.2 \mu \mathrm{l}$ red ink (text marker) or $2 \%$ Granular Blue (Ems-Polyloy)) were injected through the guide tube. This served two purposes: it indirectly visualized the site of muscimol injections. It was also a control injection that should have had no effect on the NOT-DTN.

Electrophysiology. Electrophysiological recordings in the midbrain and pretectum were performed with tungsten in glass microelectrodes. Neuronal activity was analyzed off-line. A direction selectivity index (DS) was calculated: $\mathrm{DS}=P-N / P+N$, with $P$ being the neuronal activity during stimulation in the preferred direction and $N$ the activity during stimulus movement in the nonpreferred direction. In case of retinal slip neurons, $P$ was taken as activity during ipsiversive and $N$ as activity during contraversive stimulus movement. A neuron was counted direction selective if DS $>0.2(P 50 \%$ larger than $N)$.

Visual stimulation. During the electrophysiological experiments visual stimuli consisted of single dots of light $\left(5-20^{\circ}\right.$ in diameter) and of large area random dot patterns $\left(80^{\circ}\right.$ horizontal, $60^{\circ}$ vertical extent, dot size 2 or $4^{\circ}$ ) for appropriate "full field" stimulation of retinal slip neurons in the NOT-DTN. Stimuli were projected onto a semicircular screen in front of the animal via a galvanometer-driven double-mirror system and could be moved along linear and circular paths at various velocities (Hoffmann and Schoppmann, 1981; Hoffmann and Distler, 1989). Masks could be inserted to restrict the stimulated area to the ipsilateral or contralateral hemifield. In addition, especially in the albino animals, pretectal neurons were stimulated by full field ON-OFF stimuli on the tangent screen $(26$ $\left.\mathrm{cd} / \mathrm{m}^{2}\right)$ or by direct illumination of the eyes $\left(>200 \mathrm{~cd} / \mathrm{m}^{2}\right)$ to test for visual responsiveness. A neuron was considered visual if a clear phasic response to either ON, OFF, or ON-OFF stimulation or a tonic response to light $\mathrm{ON}$ or OFF could be elicited, as judged from the sound of neuronal firing. In a number of cases, peristimulus time histograms were compiled to judge response type and strength. To quantify these responses, an ON-OFF index was calculated (ON phasic - ON spo) $/(\mathrm{ON}$ phasic - ON spo) + (OFF phasic - OFF spo), where ON and OFF phasic is the transient response to the beginning or the end of the illumination, and spo is the spontaneous discharge during continuous illumination of the screen or in darkness. An index $>0.67$ was defined as ON, an index $<0.33$ was defined as OFF, and indices in between were defined as $\mathrm{ON}-\mathrm{OFF}$ responses.

Electrical stimulation. Retinal slip neurons in the NOT-DTN were identified via their projection to the inferior olive by antidromic electrical stimulation. Two concentric stimulation electrodes (diameter, $0.3 \mathrm{~mm}$ ) were inserted into the brainstem through the foramen magnum lateral to the obex of the fourth ventricle at an angle of $45^{\circ}$ from posterior to anterior. Electrical stimulation consisted of single pulses (width, 0.1 $\mathrm{msec}$ ) that were maximally $0.5 \mathrm{~mA}$. Antidromic potentials were identified, first, by the constant latencies and shapes of the action potentials and, second, by a collision test in which spontaneous spikes were used to trigger the electrical stimulation at various delays. If the delay was equal or shorter than the latency of the antidromically elicited spike, this spike was abolished because of collision of the spontaneous and the electrically elicited spike traveling along the same axon in opposite directions.

In addition, the retinal input to antidromically identified NOT-DTN neurons was investigated by orthodromic electrical stimulation from the optic chiasm via low impedance tungsten in glass microelectrodes that first served to record visual activity from the retinal fibers.

Histology. After completion of the electrophysiological or inactivation experiments, the animals were killed with an overdose of pentobarbital 


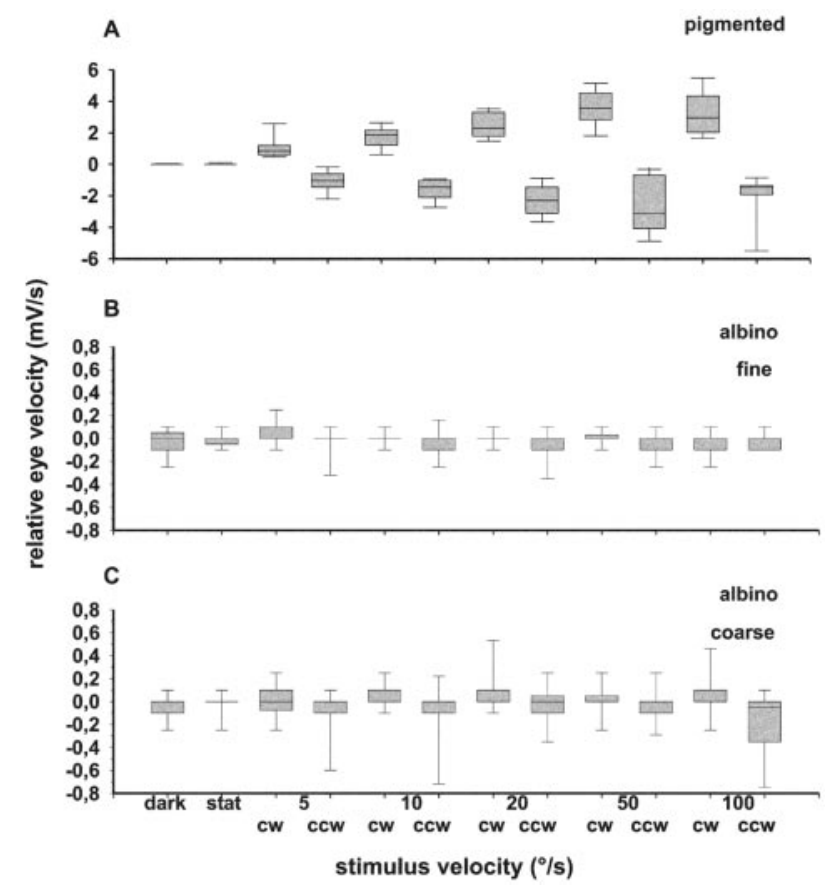

Figure 1. The velocity tuning of OKR in pigmented and albino ferrets. The median (middle mark) of the slope of the EOG signal as measure of relative eye velocity and the 25\% (bottom border of gray columns), $75 \%$ (top border of gray columns), 10\% (bottommost mark), and $90 \%$ (topmost mark) percentile is plotted versus stimulus velocity during binocular viewing. Abscissa, Stimulus velocity (in degrees per second); dark, spontaneous eye movements in darkness; stat, spontaneous eye movements while watching the stationary pattern. Ordinate, Relative eye velocity (in millivolts per second); positive values indicate eye movements during clockwise $(\mathrm{cw})$, and negative values indicate eye movements during counterclockwise (ccw) stimulation. $A$, Pigmented ferrets; $B$, albino ferrets during stimulation with the fine pattern; $C$, albino ferrets during stimulation with the coarse pattern.

and perfused through the heart with $0.9 \%$ saline and $4 \%$ paraformaldehyde. Frontal sections were cut at $50 \mu \mathrm{m}$ on a cryostat. Pretectal recording sites and the position of the stimulating electrodes or the injection cannula were verified in sections stained for Nissl and Klüver-Barrera.

\section{Results}

\section{Optokinetic reaction in pigmented ferrets}

Because OKR in pigmented ferrets has already been studied extensively by Hein et al. (1990), the OKR measurements of this strain in the present study served only two purposes, first, to determine whether our pigmented animals had a regular OKR, and second, whether OKR performance varied with the visual stimuli used. Our data showed no significant difference between stimulation with a fine or a coarse stimulus pattern. Otherwise, our results correspond to the data of Hein et al. (1990) (see Fig. $2 A, B$, right panels). Figure $1 A$ shows the median of the slope of the EOG traces taken as relative measure for eye velocity during binocular OKR of 12 pigmented ferrets tested at various stimulus velocities in clockwise and counterclockwise direction. As expected, relative eye velocity increased up to a stimulus velocity of $50 \% \mathrm{sec}$ and was more variable at higher velocities in both stimulus directions.

In none of the pigmented animals did we see spontaneous nystagmus during stationary pattern presentation or in darkness, and drifts in eye position were minimal (median of slope of EOG signal close to zero).

\section{Optokinetic reaction in albino ferrets}

Unexpectedly, we were unable to elicit regular OKR in any of the 33 albino ferrets tested. Neither monocular nor binocular stim- ulation with fine or coarse stimulus patterns produced regular slow following eye movements or resetting saccades (Fig. $2 A, B$, left panels). Also the planetarium stimulus was totally ineffective. The median of the slope of the EOG signal was close to zero in each of these conditions (Wilcoxon signed rank test and MannWhitney $U$ rank sum test, $p>0.05$ ) (Fig. $1 B, C$ ). Thus, we refer to these albino ferrets as optokinetically deficient. The drift of eye position while watching the stationary pattern or in complete darkness was similar in magnitude to the drift observed during stimulation with the moving pattern. The only indication of slight stabilizing eye movements was observed during stimulation with the coarse pattern (Fig. 1C): the direction of the slow drift of eye position was primarily the same as the direction of stimulus movement (Wilcoxon signed rank test, $p<0.05$ at 10 , 20 , and $100 \% \mathrm{sec}$ ), and the slope of the EOG signal was more variable during stimulation with the coarse than with the fine pattern.

In all albino ferrets, the median of the slopes of the EOG signal was close to zero during the control measurements with the pattern stationary or in darkness. However, the variance of the slopes was larger than in pigmented ferrets, indicating a slight instability of eye position in the albino ferret (Levene's homogeneity of variance test, $p<0.0001)$. A regular spontaneous nystagmus, unidirectional or alternating, was never observed in these animals.

\section{Optokinetic reaction in young ferrets}

To rule out that progressive retinal degeneration rendered our adult albino ferrets unable to perform OKR, we tested young albino ferrets by video observation. Do these animals shortly after eye opening (postnatal day 33-37) show OKR that then deteriorates with age? These recordings were compared with those from age-matched pigmented ferrets. Altogether, the albino pups clearly spent less time attending to the visual stimulus ("time of attention" in Table 1) at all but the fastest stimulus velocity than pigmented pups. We found that albino animals more often did not react at all or moved around without any obvious relation to the visual stimulus.

The performance of OKR was judged mainly by head movements over a period of $60 \mathrm{sec}$. Table 1 gives the average angle covered by following head (head nystagmus) or body movements (oculomotor response) and the number of these behavioral sequences in 60 sec periods. In pigmented pups, first clear following movements of the head could be elicited $3 \mathrm{~d}$ after eye opening in both stimulus directions. Slow following phases of the head followed by fast resets could best be elicited at $20-100 \% \mathrm{sec}$, whereas the slowest stimulus velocity $(10 \% \mathrm{sec})$ was mostly ineffective. Phases of visual stabilization increased in time over the test period of 4 weeks. Pigmented pups showed an increasing frequency of regular head nystagmus with slow following movements interrupted by resetting saccades with increasing age. The frequency of resetting saccades increased, the visual angle covered by each slow phase decreased with increasing stimulus velocity (see Table 1).

In contrast, the albino pups showed only turning or following head and body movements but no resetting saccades. The angle covered by these following movements was larger but less related to stimulus velocity than in pigmented animals (Table 1). A regular head nystagmus, however, could never be elicited. Although the albinos did not have any indication of regular optokinetic reactions, they showed a clear optomotor reaction (continuous turning or moving with the stimulus, OMR) comparable to that seen in normally pigmented animals. These observations lead to two conclusions: first, albino ferrets are not blind and second, 
their optokinetic defect is innate and does not develop because of a progressive degeneration of the visual pathway.

\section{Eye movements after pretectal} muscimol application

To test if the optokinetic defect in albino ferrets is caused by a motor deficiency, we injected the GABA-agonist muscimol into the vicinity of the visuomotor interface of the OKR, namely the NOT-DTN, in three albino and one pigmented ferret. We assume a push-pull system between the two NOT-DTNs in which more activity in the left NOT-DTN would drive leftward slow phases, and vice versa (Hoffmann, 1982). Muscimol would inactivate the population of neurons in one NOT-DTN e.g., driving leftward movement and the remaining activity of the neurons in the contralateral nucleus driving rightward slow phases would prevail and cause a rightward OKR (slow phase away from the injection site), regardless of whether it is driven by a visual stimulus moving in the preferred direction or not. If the defect was motor, the inactivation of the NOTDTN should not have any influence on the eye movements of albino ferrets.

Only minutes after a muscimol injection, a spontaneous nystagmus began in two albinos as well as in the pigmented animal. The slow phase of the nystagmus was directed away from the injected hemisphere (Fig. 2C), as reported for normal cats (Hoffmann and Fischer, 2001) and monkeys (Yakushin et al., 2000). The spontaneous nystagmus occurred in darkness (Fig. 2C) as well as in the presence of the stationary pattern (data not shown). It persisted at least for 2 hr but was resolved on the next day (Fig. $2 F, G$ ). Visual stimulation had a slight but consistent influence on the spontaneous nystagmus (Fig. 2D,E). Optokinetic stimulation in the direction of the spontaneous slow phases (cw for albino; ccw for pigmented) increased eye velocity, whereas stimulation in the direction opposite to the spontaneous slow phases (ccw for albino; $\mathrm{cw}$ for pigmented in Fig. 2C,D) decreased eye velocity in comparison to spontaneous nystagmus in darkness. This differential effect of the two directions of horizontal stimulation on spontaneous nystagmus strength was highly significant in the pigmented $(t=4.22$ with 33 degrees of freedom; $p<0.01)$ and in one of the two albino ferrets $(t=4.33$ with 28 degrees of freedom; $p<0.01)$ whereas it was not significant in the other $(t=1.22$ with 24 degrees of freedom; $p=0.24)$ in $t$ tests. Additional muscimol injections in these animals spaced $24-48 \mathrm{hr}$ apart showed the same effects. Therefore, a minimum of 13 measurements for each of the seven conditions in each animal went into the above statistical analysis. Altogether, the effects of the muscimol injections were reversible and highly reproducible, indicating that no lasting damage was inflicted upon the tissue. Histological reconstruction revealed that in the effective cases the guide tube was located within \pm 250 $\mu \mathrm{m}$ of the lateral anterior border of the superior colliculus, i.e., the approximate location of the NOT-DTN.
In one albino ferret muscimol injection had no effect on optokinetic eye movements. The histological reconstruction revealed that in this case the guide tube for the injection cannula was centered $600 \mu \mathrm{m}$ anterior to the rostral border of the SC. Presumably this distance was too large to involve most of the NOT-DTN into the effective spread of the muscimol injection.

Control injections with red ink or Granular Blue had no effects on eye movements in any of the animals. Thus, the spontaneous nystagmus with slow phases away from the injected side was indeed produced by the temporary inactivation by muscimol in one NOT-DTN and was not caused by an unspecific irritation of the tissue by the injection itself.

\section{Response characteristics of retinal slip neurons in the NOT-DTN of pigmented ferrets}

First, it had to be ascertained for pigmented ferrets that retinal slip neurons of the NOT-DTN that are clearly direction-selective for ipsiversive stimulus movement project to the inferior olive (IO). Altogether 37 retinal slip neurons were recorded in five pigmented ferrets ( $D S>0.2$ ) (Figs. $3 A, 4 A$ ). Of these 29 were tested by antidromic stimulation from the IO for their involvement in the OKR pathway, which could be verified for 24 cells (83\%) (Fig. 4C). A quantitative comparison of the direction selectivity index DS showed no significant difference between the antidromically identified neurons and the non-antidromically 

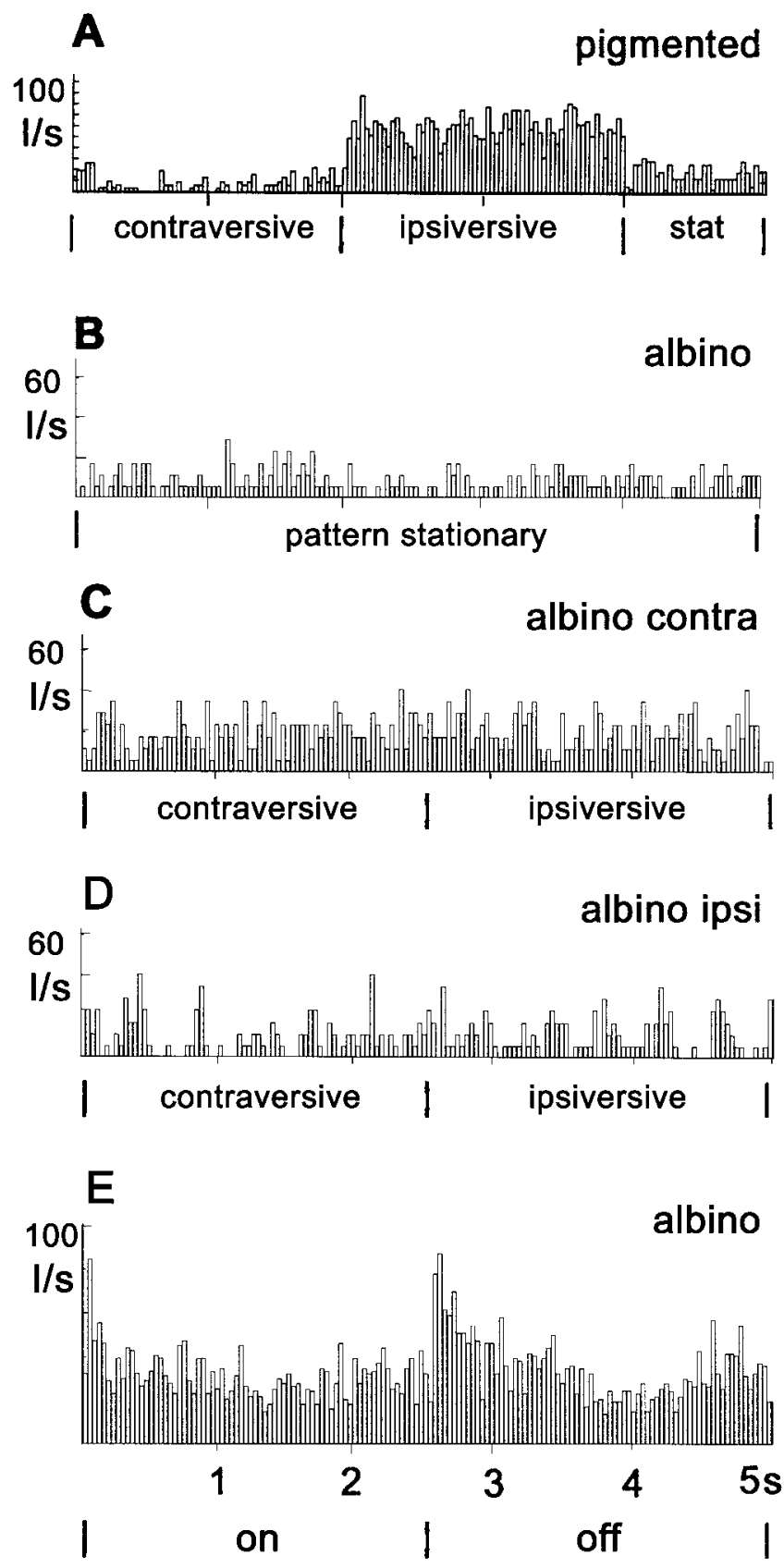

Figure 3. The response characteristics of retinal slip cells by presenting peristimulus time histograms (PSTHs) of the neuronal activity of typical cells in the NOT-DTN of a pigmented ( $A$ ) and an albino ferret $(B-E) . A, C$, and $D$ demonstrate neuronal activity during stimulation with a large area random dot pattern moving horizontally in contraversive and ipsiversive direction. Spontaneous activity was recorded while the pattern was stationary ( $B$ and "stat" in $A$ ). $B$, Albino NOT-DTN cell activity during presentation of the stationary pattern; $C$, activity during stimulation of the contralateral eye; $D$, activity during stimulation of the ipsilateral eye; $E$, the response of another putative retinal slip cell in the NOT-DTN to stimulation with a $60^{\circ}$ diameter light spot. Ordinate, Impulses per second (I/sec); abscissa, time (in seconds), also condition of stimulus movement.

identified direction selective cells (rank sum test, $p=0.933$ and $p=0.147)$. Stimulation in ipsiversive direction elicited nearly twice as many action potentials than contraversive stimulation (DS median 0.29 for the entire population) (Figs. 3A, 4A). Antidromic latencies of these direction-selective cells ranged from 1 to $8.2 \mathrm{msec}$ (median, $1.55 \mathrm{msec}$ ) (Fig. 4 C).

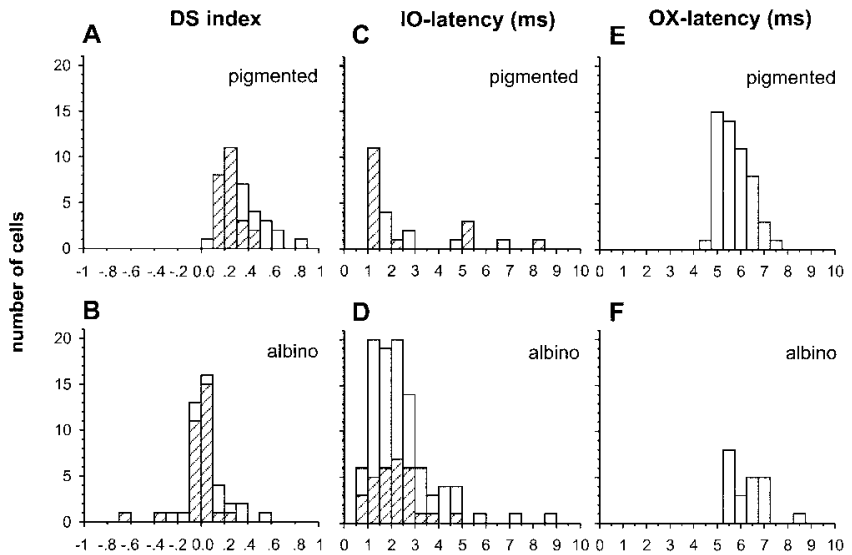

Figure 4. Direction selectivity, antidromic latencies from 10 , and orthodromic latencies from the optic chiasm OX of NOT-DTN neurons. Left panels, Frequency distribution of DS index (abscissa) of NOT-DTN neurons in pigmented $(A)$ and albino ferrets $(B)$. Positive values indicate a preference for ipsiversive, and negative values for contraversive stimulus direction. Shaded area, Antidromically identified I0-projecting neurons. Ordinate, Number of cells. Middle panels, Frequency distribution of antidromic latencies of 10 -projecting retinal slip cells in pigmented $(C)$ and albino ferrets $(D)$. Abscissa, Antidromic latencies (in milliseconds); ordinate, number of cells. Shaded areas indicate neurons for which the direction selectivity was assessed quantitatively. Right panels, Frequency distribution of orthodromic latencies from $0 \mathrm{X}$ of IO-projecting retinal slip cells in pigmented $(E)$ and albino ferrets $(F)$. Abscissa, Orthodromic latencies (in milliseconds); ordinate, number of cells.

\section{Response characteristics of retinal slip neurons in the}

\section{NOT-DTN of albino ferrets}

It can be concluded from the data in the last paragraph that NOT-DTN neurons antidromically identified from the inferior olive are direction-selective in pigmented ferrets. Does this hold true also in albino ferrets? In 16 albino ferrets, altogether 198 neurons were recorded, 193 of which were visual, i.e., they altered their activity phasically and briskly in response to ON, OFF, or $\mathrm{ON}-\mathrm{OFF}$ stimuli. By their position relative to the SC and their recording sites dorsal to so-called jerk-neurons (Ballas and Hoffmann, 1985), these 193 neurons were regarded as potential retinal slip neurons. Antidromic stimulation of 172 of the recorded neurons indeed revealed that 99 cells (58\%) projected to the IO, 94 of the 99 antidromic cells were visually responsive as defined above, i.e., their ongoing activity was modulated by visual stimulation but only through the contralateral eye.

Latencies of antidromic potentials of albino NOT-DTN cells ranged from 0.8 to $8.5 \mathrm{msec}$ with a median of $2.0 \mathrm{msec}$ (Fig. $4 D$ ). These latencies are in the same range as antidromic latencies of retinal slip cells in the NOT-DTN of pigmented ferrets (rank sum test, $p=0.965$ ). The lower ratio of antidromic cells when compared with pigmented ferrets ( 58 vs $83 \%$ ) is probably caused by the fact that direction selectivity could not be used as a criterion for identifying retinal slip cells in albinos and thus, other visual cells (not projecting to IO) could have been included in the albino sample.

Contrary to pigmented ferrets only very few directionselective cells were found among these 99 antidromic cells in albinos. Figure $3 B-D$ gives an example of an antidromically identified neuron in the albino NOT-DTN. The cell showed the typical moderate spontaneous activity ( 8.2 spikes/sec) (Fig. 3B) and was unspecifically activated when a moving random dot stimulus was presented to the contralateral eye (19.6 spikes/sec in contraversive vs 19.2 spikes/sec in ipsiversive direction) (Fig. 3C) but not when presented to the ipsilateral eye $(9.3 \mathrm{spikes} / \mathrm{sec}$ in contraversive and 10.4 spikes/sec in ipsiversive direction) (Fig. 3D). 
The activity during stimulation of the contralateral eye was significantly higher than spontaneous activity and activity during ipsilateral eye stimulation ( $p<0.0001$ in a Mann-Whitney $U$ test for both comparisons). Activity during stimulation of the ipsilateral eye was not different from spontaneous activity $(p=0.37)$. However, no significant direction-specific modulation of the activity of the cell could be elicited by the horizontal stimulus movement. Thus, this cell was visually activated by the contralateral eye only and was not direction-selective. Only when a clear visual response to the drifting random dot pattern was measurable during binocular stimulation did we test the ocular dominance also with this stimulus by compiling peristimulus time histograms. Like the cell in Figure 3, $B$ and $C$, all 12 cells tested this way were exclusively influenced from the contralateral eye, confirming our qualitative judgment in these and 181 additional cells.

To ascertain that NOT-DTN neurons were visually responsive, although often a direction-specific modulation of their ongoing activity by ipsiversive and contraversive movement of random dot patterns could not be measured, we quantitatively analyzed ON-OFF responses to intermittent whole field illumination in 27 such neurons. An example of an ON-OFF cell with an $\mathrm{ON}-\mathrm{OFF}$ index of 0.45 (for definition see Materials and Methods) is given in Figure 3E. Like this example the other 26 direction unspecific NOT-DTN neurons gave reliable responses to intermittent whole field illumination. In summary, based on their $\mathrm{ON}-\mathrm{OFF}$ index, five cells were classified as ON, 12 as ON-OFF, and 10 as OFF responding.

\section{Quantitative analysis of visual responsiveness to moving} stimuli in retinal slip cells

For 42 visual neurons, which were clearly activated by ON-OFF stimuli, the DS index was determined quantitatively during binocular stimulation. Thirty of the 42 were identified as IO projecting neurons by antidromic stimulation (Fig. $4 \mathrm{~B}$ ). The majority of the 30 IO projecting cells was not direction-specific (DS indices median: 0.0). Thus, DS indices differed significantly in pigmented and albino retinal slip cells (rank sum test, $p<0.0001$ ). This holds true also for pretectal neurons that could not be antidromically activated from the IO (rank sum test, $p<0.0001$ ). Again, there was no difference in the DS of antidromically activated cells, not activated cells, and not tested neurons (Fig. $4 B$ ) ( $p=0.338$ and $p=0.194$ ). Only three of the antidromically activated cells had a DS index $>0.2$. However, activity in two of these cells was stronger during contraversive than during ipsiversive stimulation, but only when presented to the contralateral eye.

To reveal whether the loss of direction selectivity in albino animals was secondary to a profound loss of responsiveness to moving stimuli, we present in Figure $5 A$ scatterplots, in which one axis is the response to the ipsiversive direction (in spikes per second), and the other is the response to the contraversive direction, with one point separately for each of 40 pigmented and 42 albino neurons. Because these neurons often have quite high spontaneous activity, we also plotted the responses to contraversive or ipsiversive movement against the ongoing discharge during stationary presentation of the same random dot pattern as during stimulus movement (Fig. 5B,C). For each population of neurons, a line of best fit was calculated. The correlation coefficients in linear regressions were all $>0.85$ and highly significant (all $p<0.0001)$. In all NOT-DTN neurons of pigmented ferrets, the discharge rate is higher during ipsiversive stimulus movement than during contraversive movement (Fig. 5A, black diamonds) or during presentation of the stationary pattern (Fig. $5 B$,
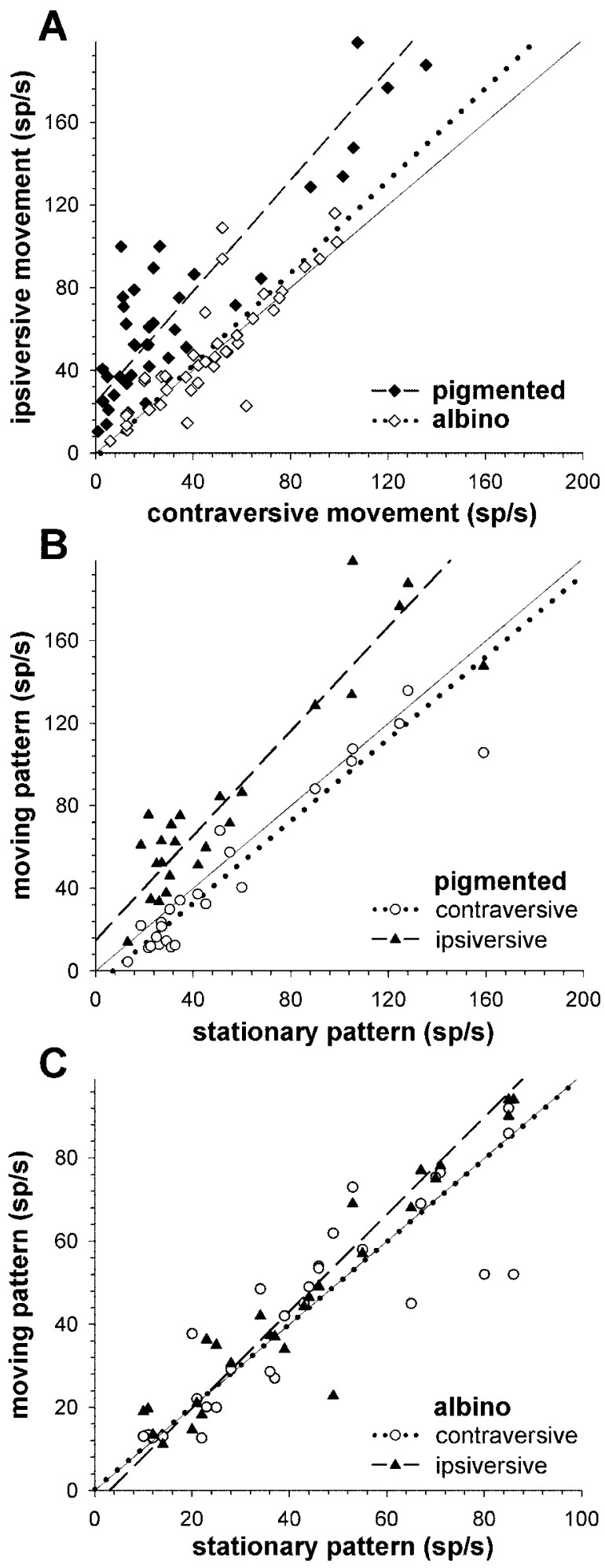

Figure 5. Scatterplots of responsiveness of NOT-DTN neurons to horizontal movement of a random dot pattern in pigmented and albino ferrets. $A$, Discharge rate during stimulation in ipsiversive (ordinate) against discharge rate during stimulation in contraversive direction (abscissa) in spikes per second (sp/sec) for pigmented (filled diamonds; dashed line) and albino ferrets (open diamonds; dotted line). The straight line indicates unity slope. B, Discharge rate as spikes per second (sp/sec) during stimulation in ipsiversive (filled triangles) and contraversive stimulus direction (open circles) is plotted on the ordinate against spontaneous activity (abscissa) in pigmented ferrets. The dashed and the dotted line are the lines of best fit for the ipsiversive and contraversive activation, respectively. C, Same as in B for albino ferrets. 
black triangles). Both differences are highly significant in a Wilcoxon signed rank test at the $p<0.0001$ level. Also the suppression of ongoing activity by stimulus movement in the contraversive direction (Fig. $5 B$, open circles) is highly significant $(p \leq 0.0005)$ in pigmented NOT-DTN neurons. The picture in albino NOT-DTN neurons is quite different. First, the discharge rate during stimulation in the preferred direction is significantly lower in albino than in pigmented NOT-DTN cells (Fig. $5 A$ ) (means: $48.5 \pm 28.4$ vs $69.5 \pm$ 46.4 spikes/sec; $p<0.02$ in a $t$ test). Second, the discharge rate during ipsiversive stimulus movement (Fig. $5 C$, black triangles) is only slightly although still significantly elevated when compared with the ongoing activity with the pattern stationary ( 48.5 vs 44.1 spikes/sec; $p<0.005$ in a Wilcoxon signed rank test). However, the ongoing activity is not suppressed during movement in contraversive direction (Fig. $5 C$, open circles). Instead it is even slightly elevated ( $41.5 \mathrm{vs}$ 46.8 spikes/sec; $p=0.45$ in a Wilcoxon signed rank test). As a consequence, there is no difference between the activity in ipsiversive and contraversive directions in many albino NOT-DTN cells (48.5 vs 46.8 spikes/sec; $p=0.45$ ). In summary, despite clear responses to $\mathrm{ON}-\mathrm{OFF}$ stimuli, the loss of direction selectivity may be secondary to a profound loss of responsiveness in more than half of the albino NOT-DTN cells. The modulation of the ongoing activity by moving stimuli is too weak to reveal covert direction-selective mechanisms. In addition most albino cells responding to moving random dot patterns are direction unselective, and the few selective cells are not biased for ipsiversive directions.

Direction selectivity of albino ferret retinal slip cells could be opposite in the temporal and nasal hemifield, similar to the findings in albino rabbits (Winterson and Collewijn, 1981). The consequence would be a bidirectional activation or cancellation falsely taken as unspecific or no response. To test for this possibility we restricted the visual stimulation to the two hemifields. The neuronal response of 48 albino NOT-DTN neurons ( 27 were antidromically identified to project to the IO) were compared during full field and ipsilateral or contralateral hemifield stimulation. Only in one case could we detect an indication of direction selectivity during ipsilateral stimulation. It was in the same ipsiversive direction as during stimulation in the contralateral hemifield. A second neuron with a contraversive preferred direction ceased responding when the stimulus was restricted to the ipsilateral hemifield. None of the direction-unselective neurons could be made direction-selective by restricting the stimulus to the contralateral or ipsilateral hemifield. Thus, the lack of a direction-selective modulation of the discharge rate documented by the low DS indices in albino ferret retinal slip cells (Fig. 4B) seems to be present in the entire visual field.

\section{Retinal input to the NOT-DTN of ferrets}

Retinal slip cells in the NOT-DTN of pigmented ferrets receive retinal input from W-ganglion cells (Fig. 4E) (Klauer et al., 1990). To test unequivocally for retinal input to antidromically identified IO projecting neurons in the NOT-DTN of albino ferrets we also electrically stimulated the optic chiasm (OX) in these animals. Of 24 neurons, 22 (92\%) could be activated, resulting in orthodromic latencies ranging between 5 and $8 \mathrm{msec}$, with a median of $6.0 \mathrm{msec}$ (Fig. $4 F$ ). This was not significantly different from OX latencies of 53 direction-selective NOT-DTN cells in pigmented ferrets (median $=5.31$; range, 4-7.5 msec; MannWhitney $U$ rank sum test; $p=0.08$ ) (Fig. $4 E$ ). Thus, NOT-DTN cells antidromically identified from IO do receive retinal input in albino ferrets. There is no indication for a reduced input strength or abnormal conduction velocity when compared with pigmented animals.

\section{Discussion}

In this study we present one of the rare examples in which an innate behavioral deficit can be related to a specific physiological alteration in the neuronal pathway subserving this particular behavior: albino ferrets lack eye movements during optokinetic stimulation because of the lack of the characteristic activation of retinal slip neurons in their NOT-DTN by ipsiversive stimulus movement. This is in contrast to neurons in the normally pigmented ferret's NOT-DTN, which are selectively activated by ipsiversive stimulus movement as well as suppressed by contraversive movement and have DS values similar to neurons in the NOT-DTN in cat or monkey (Hoffmann and Distler, 1989; Distler and Hoffmann, 1993). Therefore, in albino ferrets, no direction-selective signal, i.e., elevated activity in the left nucleus as well as suppressed activity in the right nucleus with leftward optokinetic stimulation and vice versa is generated, and thus no OKR in the appropriate direction is elicited. The albino neurophysiological defect seems to include the entire visual field. This finding is in contrast to the effects of albinism on OKR in rabbits. Here the behavioral and physiological defect is restricted to the anterior visual field in which an inversion of the direction preference of NOT-DTN neurons occurs, and as a consequence, the monocular OKR inverts.

There is a slight problem with the inversion model of Collewijn et al. (1978). The model assumes that in pigmented rabbits a significant proportion of direction-selective retinal ganglion cells from temporal retina (which are stimulated from anterior visual field and prefer nasotemporal stimulus movement) projects ipsilaterally to the NOT. These are the cells that in albino rabbits aberrantly cross and then cause the inversion of OKR after anterior field stimulation. Unfortunately, there is no anatomical evidence for a significant ipsilateral projection to the NOT in pigmented rabbits (Klooster et al., 1983). Thus, Collewijn et al. (1978) and Winterson and Collewijn (1981) already suggest an alternative explanation: a change in early retinal cell proliferation affecting direction selectivity. This change in retinal cell proliferation and specification could also lead to a loss of direction selectivity in the NOT if it would cause erroneous convergence of retinal ganglion cells with different preferred directions. The importance of proper direction coding by retinal ganglion cells for normal OKR was also shown by pharmacologically abolishing the retinal direction selectivity with GABA antagonists. This manipulation leads to severe abnormalities of the OKR in pigmented vertebrates (Bonaventure et al., 1985, 1992; Ariel et al., 1988; Ariel, 1989, 1991; Schuerger et al., 1990; Yucel et al., 1990; Ariel and Tusa, 1992; Reber et al., 1996). Whether the above discussed mechanisms, convergence of ganglion cell axons with different preferred directions or loss of direction selectivity in the retina might cause pathologically direction-unselective NOT-DTN cells in albino ferrets remains to be investigated.

Optokinetic defects have been described also in other albino mammals as well as in zebrafish (optokinetically defective mutant "sandy"; Neuhauss et al., 1999). In albino humans visual stimulation of the nasal visual field (temporal retina) can lead to OKR with the slow phases pointing into the "wrong" direction, i.e., the optokinetic reaction is inverted but there were also human albinos found with no OKR at all or even normal OKR (St. John et al., 1984; Collewijn et al., 1985). In rodents, OKR can only be elicited with certain visual stimuli (Hahnenberger, 1977; Precht and Cazin, 1979; Sirkin et al., 1985), reverses with visual stimulation in the anterior visual field or is generally depressed regardless of what part of the visual field is stimulated (Mangini et al., 1985). Taken together these findings imply that there is not 
just one effect of albinism on eye movements and that these effects can vary within and between species.

Why then study OKR in albino ferrets? OKR in albino carnivorous strains has not been tested so far, and albino ferrets are more readily available than albino cats or even primates. Normally pigmented ferrets have a large binocular visual field and show a largely symmetrical monocular OKR. Their mostly binocular NOT-DTN neurons are rendered monocular by visual deprivation and are under strong cortical influence. All these properties support the notion that the visual part of the optokinetic system in this species is very similar to that in cats and primates (Hein et al., 1990; Klauer et al., 1990; Sengpiel et al., 1990). Unfortunately, we have no information about the organization of the optokinetic system in fast and slow pathways beyond the visual structures. Thus, the major advantage of studying OKR in albino ferrets is their more human like visual system when compared with rodents and rabbits. Because of the well established reduction of binocular neurons in the visual cortex of albinos (Siamese cats: e.g., Cool and Crawford, 1972; Antonini et al., 1981; Di Stefano et al., 1984; Toyama et al., 1991; ferret: Akerman et al., 2003), we expected and found a loss of binocularity in the NOT-DTN of albino ferrets based on our model published in 1982 (Hoffmann, 1982). The profound reduction of responsiveness to moving stimuli despite good responses to intermittent light stimuli in many retinal slip cells of the NOTDTN as well as the loss of direction selectivity for ipsiversive movement in the responsive cells came as a surprise, but of course these findings are totally in agreement with the complete lack of OKR in albino ferrets. These changes are particularly puzzling because strong responsiveness and direction selectivity of NOTDTN neurons up to now seemed to be very robust properties surviving strabismus (Cynader and Hoffmann, 1981; Distler and Hoffmann, 1996), deprivation (Hoffmann, 1983; Grasse and Cynader, 1986, 1987; Sengpiel et al., 1990), eye rotation (Hoffmann et al., 1995), and decortication (Hoffmann 1982; Grasse et al., 1984).

Temporary inactivation of the albino ferret NOT-DTN on one side of the brain by muscimol injection caused spontaneous nystagmus with the slow phases away from the inactivated hemisphere, indicating that the downstream part of the pathway is intact. This interpretation is also supported by anatomical findings after tracer injections into the IO where we found comparable numbers of retrogradely labeled neurons in the NOT-DTN in pigmented and albino ferrets (Telkes et al., 2001), as well as by the fact that we could antidromically identify neurons in the NOTDTN by electrical stimulation in the IO with about equal latencies. Thus, the neuronal substrate for the OKR, namely neurons projecting to the brain stem, is present in both pigmented and albino ferrets.

The lack of eye movements during optokinetic stimulation in albino ferrets is difficult to reconcile with the other known effects of albinism on the visual system. There are several retinal aberrations caused by albinism (Jeffery, 1997), a reduction of ipsilaterally projecting retinofugal axons (Morgan et al., 1987; Zhang and Hoffmann 1993), an aberrant, albeit well developed retinal projection to subcortical visual structures, a distorted retinotopic map in visual cortex but not in the superior colliculus (Quevedo et al., 1996; Akerman et al., 2003), as well as a lack of binocular neurons in visual cortex. None of these changes seem to have direct bearing on the lack of OKR. Direction selectivity could be abolished in the NOT-DTN because of direction-unspecific input, unspecific convergence of otherwise direction-selective cells from retina and cortex, or lack of direction-specific inhibition in the NOT-DTN itself. These issues have to be resolved by further experiments, but it seems clear that the tyrosinase gene mutation must have so far not described additional effects on the brain of albinos. Initial support for such a suggestion comes from the morphological changes reported for neurons in the medial superior olive of the acoustic system (Conlee et al., 1986) and by our own recently published results on reduced dendritic arborisation and length in the NOT-DTN (Telkes et al., 2001). These NOTDTN neurons that developed incorrectly may also show physiological aberrations that lead to the loss of their characteristic selectivity for the direction of retinal slip and as a consequence this structure cannot generate a signal for OKR during optokinetic stimulation.

\section{References}

Akerman CJ, Tolhurst DJ, Morgan JE, Baker GE, Thompson ID (2003) The relay of visual information to the lateral geniculate nucleus and the visual cortex in albino ferrets. J Comp Neurol 461:217-235.

Antonini A, Berlucchi G, Di Stefano M, Marzi CA (1981) Differences in binocular interactions between cortical areas 17 and 18 and superior colliculus of Siamese cats. J Comp Neurol 200:597-611.

Ariel M (1989) Analysis of vertebrate eye movements following intravitreal drug injections: III. Spontaneous nystagmus is modulated by the GABAa receptor. J Neurophysiol 62:469-480.

Ariel M (1991) Analysis of vertebrate eye movements following intravitreal drug injections: IV. Drug-induced eye movements are unyoked in the turtle. J Neurophysiol 65:1003-1009.

Ariel M, Tusa RJ (1992) Spontaneous nystagmus and gaze-holding ability in monkeys after intravitreal picrotoxin injections. J. Neurophysiol 67:1124-1132.

Ariel M, Robinson FR, Knapp AG (1988) Analysis of vertebrate eye movements following intravitreal drug injections: II. Spontaneous nystagmus induced by picrotoxin is mediated subcortically. J Neurophysiol 60:1022-1035.

Ballas I, Hoffmann K-P (1985) A correlation between receptive field properties and morphological structures in the pretectum of the cat. J Comp Neurol 238:417-428.

Bonaventure N, Wioland N, Jardon B (1985) On GABAergic mechanisms in the optokinetic nystagmus of the frog: effects of bicuculline, allylglycine and SR 95103, a new GABA antagonist. Eur J Pharmacol 118:61-68.

Bonaventure N, Kim MS, Jardon B, Yucel H (1992) Pharmacological study of the chicken's monocular optokinetic nystagmus: effects of GABAergic agonists and antagonists. Vision Res 32:611-620.

Collewijn H (1975) Direction selective neurons in the rabbit's nucleus of the optic tract. Brain Res 100:489-508.

Collewijn H, Winterson BJ, Dubois MFW (1978) Optokinetic eye movements in albino rabbits: inversion in the anterior visual field. Science 199:1351-1353.

Collewijn H, Apkarian P, Spekreijse H (1985) The oculomotor behaviour of human albinos. Brain 108:1-28.

Conlee JW, Parks TN, Creel DJ (1986) Reduced neuronal size and dendritic length in the medial superior olivary nucleus of albino rabbits. Brain Res 363:28-37.

Cool SJ, Crawford ML (1972) Absence of binocular coding in striate cortex units of Siamese cats. Vision Res 12:1809-1814.

Cynader M, Harris L (1980) Eye movement in strabismic cats. Nature 286:64-65

Cynader M, Hoffmann K-P (1981) Strabismus disrupts binocular convergence in cat nucleus of the optic tract. Dev Brain Res 1:132-136.

Di Stefano M, Bedard S, Marzi CA, Lepore F (1984) Lack of binocular activation of cells in area 19 of the Siamese cat. Brain Res 303:391-395.

Distler C, Hoffmann K-P (1993) Visual receptive field properties in kitten pretectal nucleus of the optic tract and dorsal terminal nucleus of the accessory optic tract. J Neurophysiol 70:814-827.

Distler C, Hoffmann K-P (1996) Retinal slip neurons in the nucleus of the optic tract and dorsal terminal nucleus in cats with congenital strabismus. J Neurophysiol 75:1483-1494.

Grasse KL, Cynader MS (1986) Response properties of single units in the accessory optic system of the dark-reared cat. Brain Res 392:199-210.

Grasse KL, Cynader MS (1987) The accessory optic system of the monocularly deprived cat. Brain Res 428:229-241. 
Grasse KL, Cynader MS, Douglas RM (1984) Alterations in response properties in the lateral and dorsal terminal nuclei of the cat accessory optic system following visual cortex lesions. Exp Brain Res 55:69-80.

Hahnenberger RW (1977) Differences in optokinetic nystagmus between albino and pigmented rabbits. Exp Eye Res 25:9-17.

Hein A, Courjon JH, Flandrin JM, Arzi M (1990) Optokinetic nystagmus in the ferret: including selected comparisons with the cat. Exp Brain Res 79:623-632.

Hoffmann K-P (1982) Cortical versus subcortical contributions to the optokinetic reflex in the cat. In: Functional basis of ocular motility disorders (Lennerstrand G, Zee DS, Keller EL, eds), pp 303-310. Oxford, New York, Pergamon.

Hoffmann K-P (1983) Effects of early monocular deprivation on visual input to cat nucleus of the optic tract. Exp Brain Res 51:236-246.

Hoffmann K-P, Distler C (1989) Quantitative analysis of visual receptive fields of neurons in the nucleus of the optic tract and dorsal terminal nucleus of the accessory optic tract in macaque monkeys. J Neurophysiol 62:416-428.

Hoffmann K-P, Fischer WH (2001) Directional effect of inactivation of the nucleus of the optic tract on optokinetic nystagmus in the cat. Vision Res 41:3389-3398.

Hoffmann K-P, Schoppmann A (1981) A quantitative analysis of directionspecific responses of neurons in the cat's nucleus of the optic tract. Exp Brain Res 42:146-157.

Hoffmann KP, Stone J (1985) Retinal input to the nucleus of the optic tract of the cat assessed by antidromic activation of ganglion cells. Exp Brain Res 59:395-403.

Hoffmann K-P, Distler C, Mark RF, Marotte LR, Henry G, Ibbotson MR (1995) Neural and behavioral effects of early eye rotation on the optokinetic system in the wallaby, Macropus eugenii. J Neurophysiol 73:727-735.

Ilg UJ, Bremmer F, Hoffmann K-P (1993) Optokinetic and pursuit system: a case report. Behav Brain Res 57:21-29.

Inoue Y, Takamura A, Kawano K, Mustari MJ (2000) Role of the pretectal nucleus of the optic tract in short-latency ocular following responses in monkeys. Exp Brain Res 131:269-281.

Jeffery G (1997) The albino retina: an abnormality that provides insight into normal retinal development. Trends Neurosci 20:165-169.

Kato I, Harada K, Hasegawa T, Igarashi T (1988) Role of the nucleus of the optic tract in monkeys in optokinetic nystagmus and optokinetic afternystagmus. Brain Res 474:16-26.

Klauer S, Sengpiel F, Hoffmann K-P (1990) Visual response properties and afferents of nucleus of the optic tract in the ferret. Exp Brain Res $83: 178-189$

Klooster J, van der Want JJ, Vrensen G (1983) Retinopretectal projections in albino and pigmented rabbits: an autoradiographic study. Brain Res 288:1-12.

Magnin M, Kennedy H, Hoffmann K-P (1989) A double-labeling investigation of the pretectal visuo-vestibular pathways. Vis Neurosci 3:53-58.

Mangini NJ, Vanable Jr JW, Williams MA, Pinto LH (1985) The optokinetic nystagmus and ocular pigmentation of hypopigmented mouse mutants. J Comp Neurol 241:191-209.
Morgan JE, Henderson Z, Thompson ID (1987) Retinal decussation patterns in pigmented and albino ferrets. Neuroscience 20:519-535.

Neuhauss SCF, Biehlmaier O, Seeliger MW, Das T, Kohler K, Harris WA, Baier H (1999) Genetic disorders of vision revealed by a behavioral screen of 400 essential loci in zebrafish. J Neurosci 19:8603-8615.

Precht W, Cazin L (1979) Functional deficits in the optokinetic system of albino rats. Exp Brain Res 37:183-186.

Quevedo C, Hoffmann K-P, Husemann R, Distler C (1996) Overrepresentation of the central visual field in the superior colliculus of the pigmented and albino ferret. Vis Neurosci 13:627-638.

Reber A, Poitevin B, Leroy MH, Nzobounsana V (1996) Optokinetic and vestibulo-ocular reflex adjustment by GABA antagonists. Behav Brain Res 81:89-97.

Schiff D, Cohen B, Raphan T (1988) Nystagmus induced by stimulation of the nucleus of the optic tract in the monkey. Exp Brain Res 70:1-14.

Schiff D, Cohen B, Büttner-Ennever J, Matsuo V (1990) Effects of lesions of the nucleus of the optic tract on optokinetic nystagmus and afternystagmus in the monkey. Exp Brain Res 79:225-239.

Schuerger RJ, Rosenberg AF, Ariel M (1990) Retinal direction-sensitive input to the accessory optic system: an in vitro approach with behavioral relevance. Brain Res 522:161-164.

Sengpiel F, Klauer S, Hoffmann KP (1990) Effects of early monocular deprivation on response properties and afferents of nucleus of the optic tract in the ferret. Exp Brain Res 83:190-199.

Simpson JI, Giolli RA, Blanks RHI (1988) The pretectal nuclear complex and the accessory optic system. In: Neuroanatomy of the oculomotor system (Büttner-Ennever JA, ed), pp 333-362. Amsterdam: Elsevier.

Sirkin DW, Hess BJ, Precht W (1985) Optokinetic nystagmus in albino rats depends on stimulus pattern. Exp Brain Res 61:218-221.

St. John R, Fisk JD, Timney B, Goodale MA (1984) Eye movements in human albinos. Am J Optom Physiol Optics 61:377-385.

Taylor RB, Wennberg RA, Lozano AM, Sharpe JA (2000) Central nystagmus induced by deep brain stimulation for epilepsy. Epilepsia 41:1637-1641.

Telkes I, Garipis N, Hoffmann K-P (2001) Morphological changes in the neuronal substrate for the optokinetic reflex in albino ferrets. Exp Brain Res 140:345-356.

Toyama K, Kitaoji H, Umetani K (1991) Binocular neuronal responsiveness in Clare-Bishop cortex of Siamese cats. Exp Brain Res 86:471-482.

Winterson BJ, Collewijn H (1981) Inversion of direction-selectivity to anterior fields in neurons of nucleus of the optic tract in rabbits with ocular albinism. Brain Res 220:31-49.

Yakushin SB, Reisine H, Buttner-Ennever J, Raphan T, Cohen B (2000) Functions of the nucleus of the optic tract (NOT). I. Adaptation of the gain of the horizontal vestibulo-ocular reflex. Exp Brain Res 131:416-432.

Yucel YH, Jardon B, Kim MS, Bonaventure N (1990) Directional asymmetry of the horizontal head and eye optokinetic nystagmus: effects of picrotoxin. Vision Res 30:549-555.

Zhang HY, Hoffmann K-P (1993) Retinal projections to the pretectum, accessory optic system and superior colliculus in pigmented and albino ferrets. Eur J Neurosci 5:486-500. 